\title{
Ser y no parecer: el misterio de un corazón engañoso
}

\author{
Lizbel Esteban Milla* \\ Pedro Yanac Chávez* \\ Zoila Rodríguez Urteaga** \\ Carlos Fuentes Ortega**
}

* Hospital Alberto Sabogal Sologuren. Lima. Perú

** Instituto Nacional Cardiovascular "Carlos Alberto Peschiera". Lima. Perú

Recibido: 26/04/2020

Aceptado: 13/10/2020

En línea: 31/12/2020

\section{Correspondencia}

Lizbel Esteban Milla

lizbelem@gmail.com

Citar como: Esteban Milla L, Yanac Chávez P, Rodríguez Urteaga Z, Fuentes Ortega C. Ser y no parecer: el misterio de un corazón engañoso. Rev Ecocar Pract (RETIC). 2020 (Dic); 3 (3): 30-32. doi: 10.37615/retic.v3n3a12.

Cite this as: Esteban Milla L, Yanac Chávez P, Rodríguez Urteaga Z, Fuentes Ortega C. Being and not looking alike: a deceptive heart mystery. Rev Ecocar Pract (RETIC). 2020 (Dic); 3 (3): 30-32. doi: 10.37615/retic.v3n3a12.

\begin{tabular}{l} 
Palabras clave \\
$\triangleright$ Complejo de Shone \\
$\triangleright$ Reporte de caso \\
$\triangleright$ Cardiopatía congénita \\
$\triangleright$ Adulto \\
\hline Keywords \\
$\triangleright$ Shone complex \\
$\triangleright$ Case report \\
$\triangleright$ Congenital heart disease \\
$\triangleright$ Adult \\
\hline
\end{tabular}

\section{Presentación del caso}

Varón de 70 años de edad con antecedentes de hipertensión arterial en tratamiento regular y que tuvo una reparación quirúrgica de coartación aórtica hacía 50 años, de la que no hay registros adicionales. Acudió de manera ambulatoria por episodios de disnea a medianos esfuerzos.

El electrocardiograma nos mostraba ritmo sinusal e imágenes de hemibloqueo anterior izquierdo y bloqueo de rama derecha con algunas contracciones ventriculares prematuras.

En la ecocardiografía transtorácica (ETT) (Vídeo 1 y Vídeo 2), llamaba la atención la dilatación de la aurícula izquierda, la morfología del ventrículo izquierdo, y un flap de los extremos distales de las cuerdas tendíneas.

La ecocardiografía transesofágica (ETE) reveló también la presencia de una membrana incompleta que se ubicaba sobre el plano valvular mitral (Vídeo 3 y Vídeo 4) con fisiología de estenosis leve a moderada y que las cuerdas tendinosas convergían en un músculo papilar único, configurando así la válvula mitral en paracaídas con gradiente medio de $5 \mathrm{mmHg}$ y área valvular mitral 1,83 $\mathrm{cm}^{2}$ por tiempo de hemipresión (Vídeo 5). La reconstrucción 3D nos permitió ver la discontinuidad de la membrana (Vídeo 6), que justificaba la repercusión hemodinámica leve que había tenido el paciente. Para el estudio de la aorta, se realizó una tomografía, donde incidentalmente se describió el nacimiento anómalo de la arteria circunfleja desde el seno no coronario con trayecto retroaórtico y retroauricular alto que condicionaba una muesca en la aurícula izquierda (Vídeo 7 y Figura 1). Además, se logró observar una membrana mitral pequeña a nivel del festón A1 que estaría produciendo la estenosis (Figura 2). Respecto al estado posquirúrgico de la coartación, había un estrechamiento relativo a nivel diafragmático de aproximadamente 30\% (Vídeo 8).

\section{Estudio por imagen}

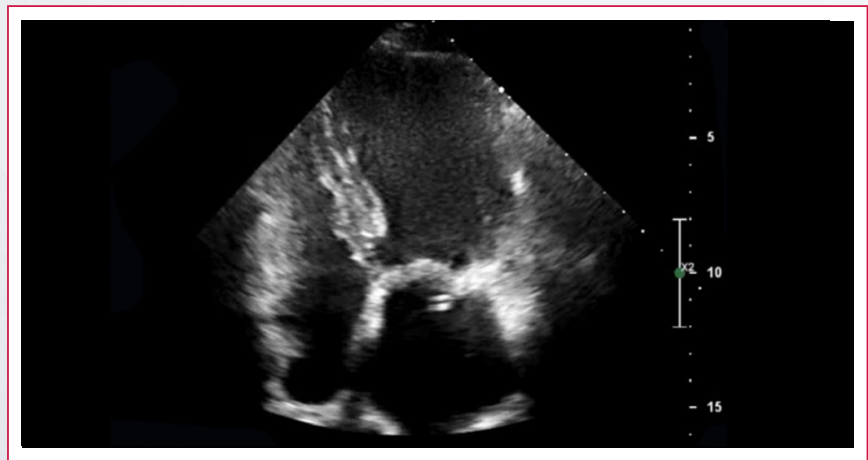

Vídeo 1. ETT en apical 4 cámaras donde se observa dilatación de aurícula izquierda 


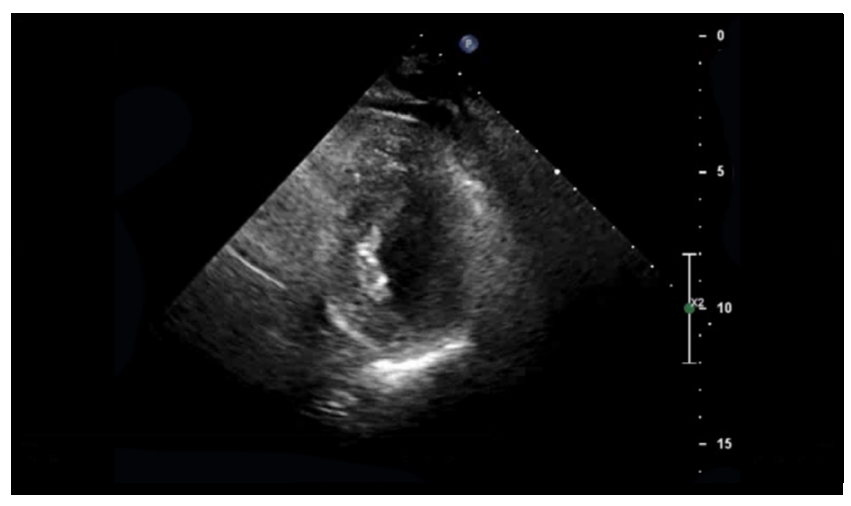

Vídeo 2. ETT en eje corto a nivel de músculos papilares donde se observa válvula mitral en paracaídas

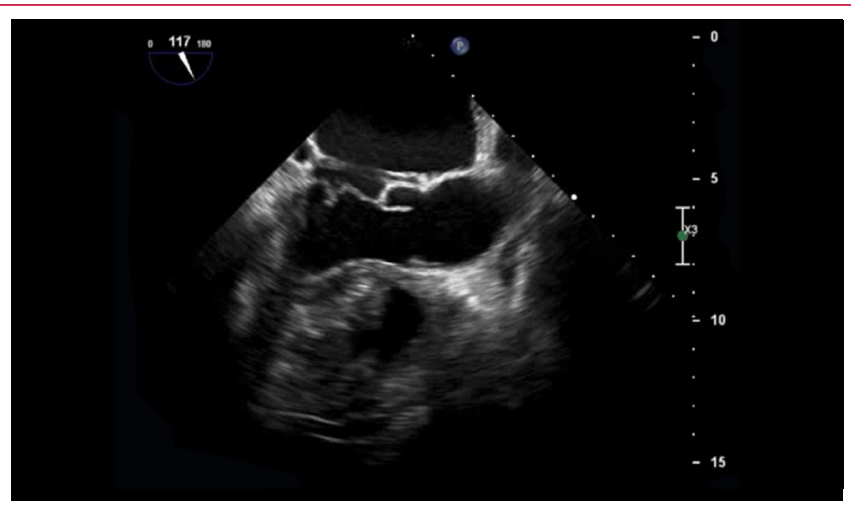

Vídeo 3. ETE a 1170 con imagen sugestiva de membrana supravalvular mitral

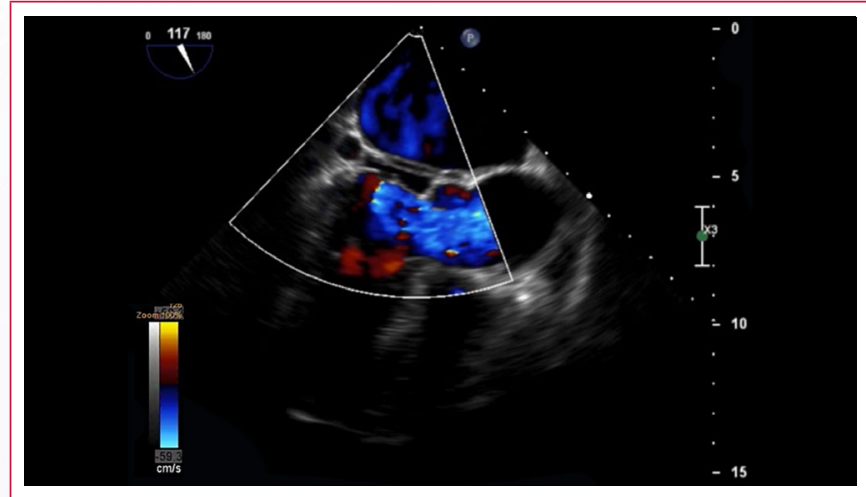

Vídeo 4. Membrana valvular condiciona estenosis leve-moderada (gradiente $5 \mathrm{mmHg}$ )

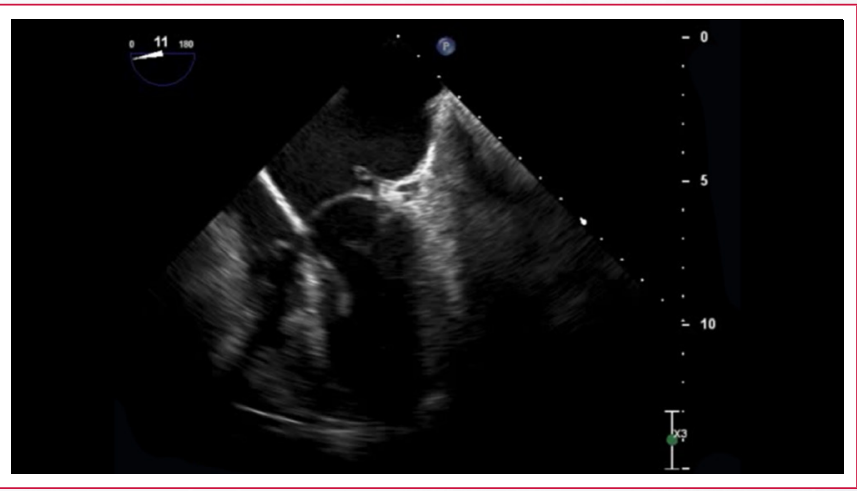

Vídeo 5. ETE a 11․ Nótese imagen incompleta de membrana supravalvular mitrall

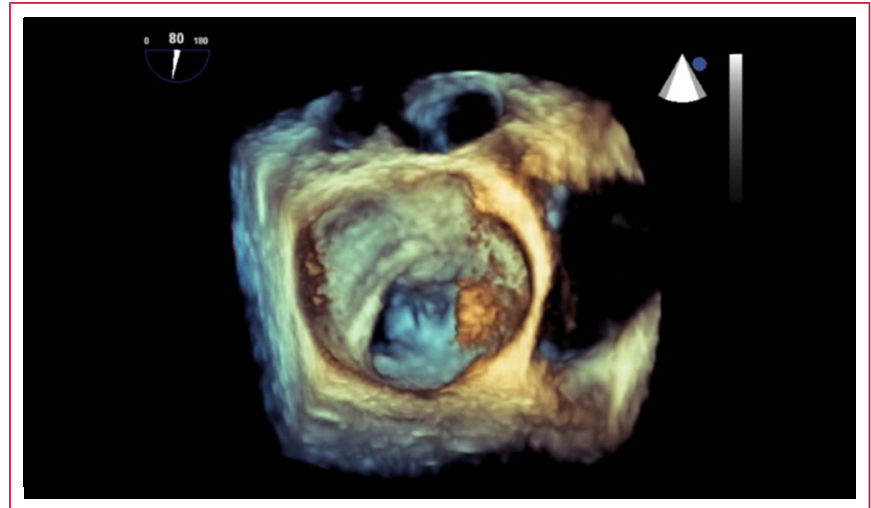

Vídeo 6. Reconstrucción 3D de membrana supravalvular mitral incompleta

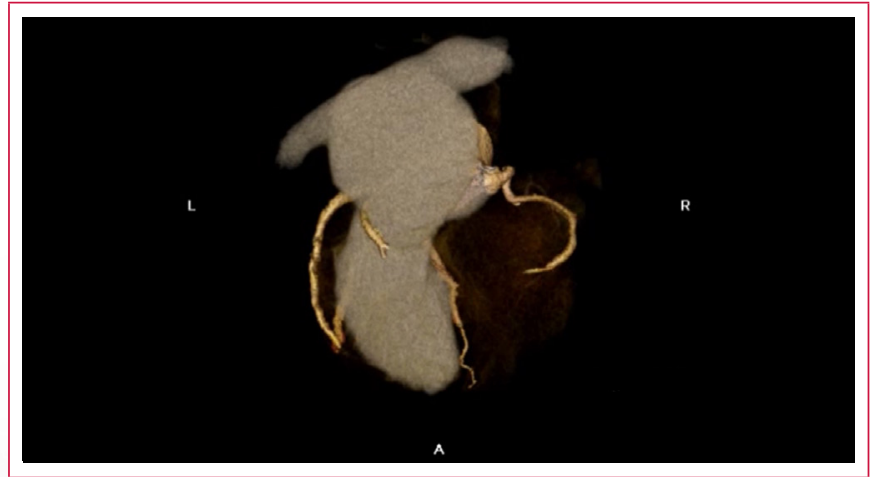

Vídeo 7. Tomografía con reconstrucción tridimensional de arterias coronarias. Nótese ausencia de tronco coronario izquierdo, arteria circunfleja de nacimiento alto desde seno no coronario, y de trayecto retroaórtico y retroauricular

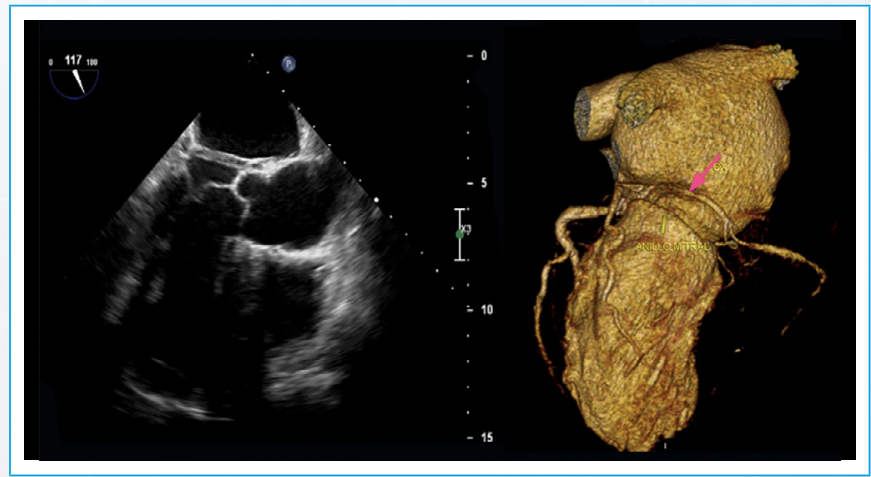

Figura 1. Correlación anatómica de tomografía y ecocardiografía. Imagen que inicialmente impresionaba membrana supravalvular mitral resultó ser el trayecto anómalo de la arteria circunfleja (flecha rosada)

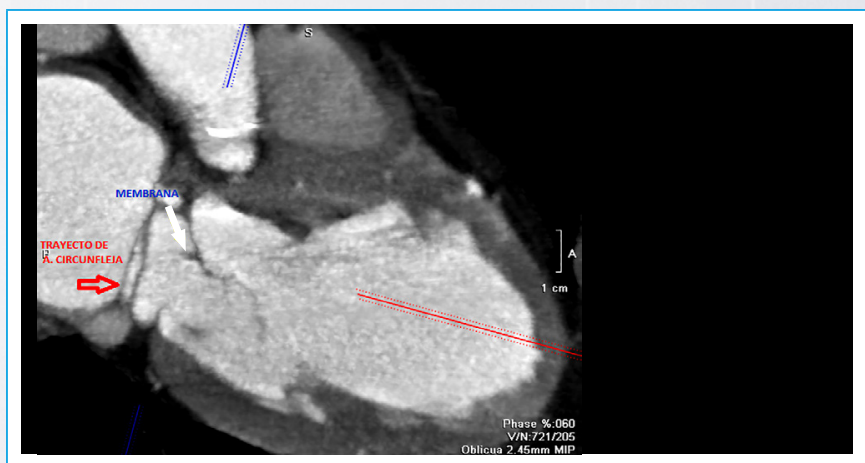

Figura 1. Tomografía cardíaca que evidencia membrana mitral a nivel del festón A1 (flechablanca) 


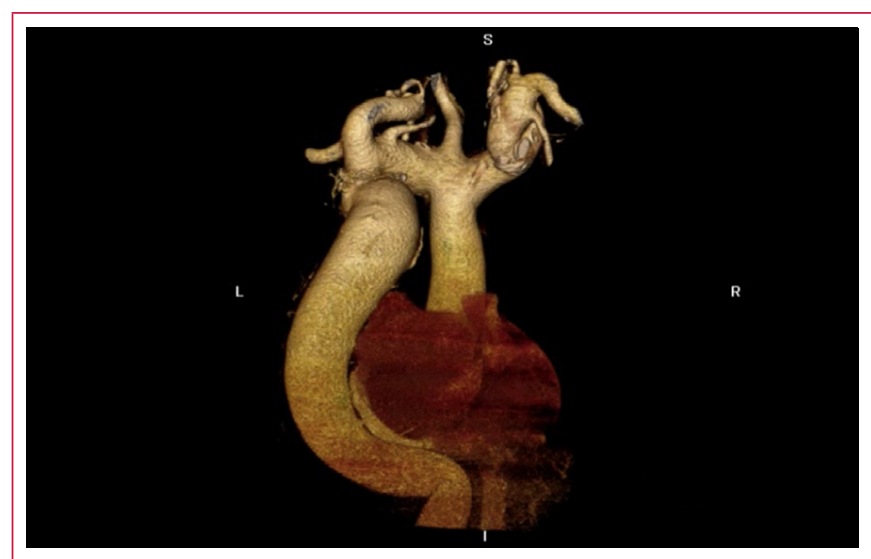

Vídeo 8. Reconstrucción tomográfica de coartación de aorta tratada de manera quirúrgica hace 50 años con estenosis diafragmática no significativa

\section{Discusión}

En 1963, el cardiólogo pediatra J. D. Shone describió por primera vez un grupo de ocho pacientes, en su mayoría pediátricos, que presentaban alteraciones estructurales y que comprometían el tracto de entrada y el de salida del ventrículo izquierdo; fueron un total de cuatro: válvula mitral en paracaídas, anillo supravalvular mitral, estenosis subaórtica y coartación de aorta ${ }^{(1)}$.

Desde entonces, el conocimiento de este síndrome se ha basado en reportes de casos aislados y algunas pocas cortes retrospectivas. El Instituto de Montreal ${ }^{(2)}$ reunió 28 pacientes entre 1982 y 2014 con una prevalencia de 0,67\% de los cuales sólo uno presentaba el complejo en su totalidad. La edad media fue 35 años sin preferencia de sexo, y lo novedoso de este trabajo es el seguimiento a 8 años, ya que aporta información pronóstica desconocida hasta el momento y sustenta lo que vimos en el caso, que la indicación quirúrgica más frecuente es la coartación aórtica. Postulan además que, al coexistir la obstrucción mitral y la coartación, hay predominio de una de ellas.

La ecocardiografía tridimensional permite la reconstrucción multiplanar en casos de dudas diagnósticas. Se podrían incluir como diagnósticos diferenciales el cortriatriatum, el propaso valvular mitral o la presencia de vegetaciones. El uso de ETE en este caso ha propuesto el término anillo valvar, para algunas variantes del síndrome de Shone ${ }^{(3)}$, en las que la membrana se presenta al mismo nivel de las valvas y condiciona la estenosis, como sería en nuestro caso. Inicialmente estábamos convencidos de la presencia fija de una membrana incompleta, sin embargo la imagen de tomografía nos reveló el trayecto inusual de la arteria circunfleja que deformaba de forma intermitente al atrio izquierdo y la verdadera localización de la membrana; esto fue posible gracias al advenimiento de las nuevas técnicas de imagen con las que se pueden describir con mayor precisión las estructuras intra o extracardíacas y conocer lesiones asociadas que incrementarían las posibilidades diagnósticas ${ }^{(4)}$.

\section{Conclusión}

El presente caso es una forma incompleta del complejo de Shone que ha permitido la sobrevida libre de eventos cardiovasculares y es reflejo del gran aporte que representan las nuevas técnicas de imagen en el ámbito de la cardiología.

\section{Ideas para recordar}

- La evolución de las técnicas de imágenes cardíacas permite un mejor diagnóstico, tratamiento y seguimiento en cardiopatías complejas.

- De existir antecedente, diagnóstico o tratamiento de coartación de aorta, debe realizarse el estudio de alteraciones estructurales del complejo de Shone.

- Los exámenes de apoyo diagnóstico son complementarios entre sí y, aunados a la clínica, son fuentes invaluables de información.

\section{Bibliografía}

1. Shone JD, Sellers RD, Anderson RC, Adams P Jr, Lillehei CW, Edwards JE. The developmental complex of "parachute mitral valve" supravalvular ring of left atrium, subaortic stenosis, and coarctation of aorta. Am J Cardiol 1963; 11:714-725,

2. Aslam S, Khairy P, Shohoudi A, Mercier LA, Dore A, Marcotte F, Miró J, AvilaAlonso P, Ibrahim R, Asgar A, Poirier N, Mongeon FP. Shone complex: an under-recognized congenital heart disease with substantial morbidity in adulthood. Canadian Journal of Cardiology 2016.

3. Vivas MF, Politi MT, Riznyk LM, Castro MF, Avegliano G, Ronderos R. Shone's syndrome: insights from three-dimensional echocardiography. Echocardiography 2017; 00: 1-3.

4. True A, Baidya M, Lui C, Kilimnik G, Sadler M. Computed tomography imaging characteristics of shone syndrome. Radiology Case Reports 2019; 14 (2): 164-167. 